\title{
Do espaço ao ciberespaço: sobre etnografia e netnografia
}

Rafael Fernandes de Mesquita

Doutorando do Programa de Pós-Graduação em Administração de Empresas da Universidade Potiguar - UnP. Professor do Instituto Federal do Piauí - IFPI

Fátima Regina Ney Matos

Doutora em Administração de Empresas (UFPE) e Professora do Programa de Pós-Graduação em Administração de Empresas da Universidade Potiguar - UnP/Brasil. Professora do Instituto Superior Miguel Torga/Portugal.

Diego de Queiroz Machado

Doutor em Administração de Empresas pela Universidade de Fortaleza - UNIFOR e Professor da Universidade Federal do Ceará - UFC

Augusto Marcos Carvalho de Sena

Ph.D. em Economia pela University of New Hampshire, EUA. Professor da Universidade de Fortaleza - UNIFOR e da Universidade Federal do Ceará - UFC.

Maria Manuel Rocha Teixeira Baptista

Professora auxiliar com agregação da Universidade de Aveiro e diretora do Programa Doutoral em Estudos Culturais das Universidades de Aveiro e do Minho.

http://dx.doi.org/10.1590/1981-5344/2998

Este trabalho tem como objetivo analisar a evolução das pesquisas em netnografia, a partir da aplicação de uma análise bibliométrica nas produções científicas na área. Para essa análise, optou-se pela utilização da base de dados Web of Science ${ }^{T M}$, principalmente pela sua abrangência ao conter inúmeras áreas científicas. Como principais resultados das análises foram identificadas a quantidade de artigos em evolução atingindo seu ápice no ano de 2015, os top journals, países e autores da temática e os artigos mais citados que apresentam 
objetos empíricos distintos, sem problematizar o uso e a adaptação do método etnográfico às comunidades on-line. Ao concluir o trabalho, o estudo propõe indicativos de uma agenda de pesquisa para discutir o método e suas implicações para os estudos das organizações e a área que é majoritariamente o campo das pesquisas netnográficas: o marketing.

Palavras-chave: Netnografia. Etnografia. Web of Science. Bibliometria.

\section{From space to cyberspace: on ethnography and netnography}

This work aims to analyze the evolution of the researches in netnography, from the application of a bibliometric analysis in the scientific productions in the area. For this analysis, we opted for the use of the Web of Science ${ }^{T M}$ database, mainly due to its wide range of scientific areas. The main results of the analyzes were the number of articles in evolution reaching their apex in the year 2015, the top journals, countries and authors of the subject and the most cited articles that presents different empirical objects, without problematizing the use and adaptation of the method to online communities. At the conclusion of the work, the study proposes a research agenda to discuss the method and its implications for the studies of organizations and the area that is mostly the field of netnographic research: marketing.

Keywords: Netnography. Ethnography. Web of Science. Bibliometrics.

Recebido em 14.11.2016 Aceito em 07.05.2018

\section{Introdução}

Nas últimas duas décadas, a internet vem transformando a vida social através das suas diversas ferramentas tecnológicas, criando um ambiente virtual de interação no qual a sociedade e seus indivíduos atuam continuamente. Diante da habitualidade com que as ações do espaço físico são substituídas por ações no ambiente virtual, elementos culturais também avançam para o ciberespaço, culminando com o surgimento da assim chamada cibercultura. 
Acompanhando o surgimento desse novo fenômeno social, as metodologias de investigação em ciências sociais também têm se desenvolvido, dando origem a novos métodos de pesquisa que permitem avançar na exploração destes novos ambientes culturais humanos, como é o caso da netnografia. Inicialmente, a netnografia se apresenta como uma variação da já conhecida etnografia, originada na Antropologia Social com os estudos de Malinowski (1978), e que corresponde ao estudo aprofundado de comunidades com o intuito de compreender seu estilo de vida e cultura (CAVEDON, 2003). Quanto à netnografia, cujo termo foi utilizado primeiramente por Kozinets (1997), corresponde ao estudo de comunidades virtuais, visando o conhecimento acerca de sua cibercultura.

No entanto, apesar da aparente relação entre essas duas metodologias, há questionamentos acerca do uso do neologismo netnografia. Neste contexto, por exemplo, denotam-se os limites em que os imponderáveis da vida real podem ser realmente transformados em imponderáveis do mundo virtual, tendo em vista que são fenômenos que só poderiam ser compreendidos em sua essência por meio da observação em seu contexto real (MALINOWSKI, 1978).

Ademais, a ciência possui excelência presumida e, se não questionada, doutrinária (FEYERABEND, 1989). Morin (1996) atenta para o caráter dogmático da ciência quando, em conformidade com Popper (1999), diz que a ciência é biodegradável, e uma teoria torna-se científica quando sua falsidade pode eventualmente ser demonstrada. $O$ método ou a ciência não irrefutáveis, invencíveis, devem ser questionados, e assim o conhecimento avança (MESQUITA; MATOS, 2014). A potencialidade de mudança e construção de conhecimento, da qual o pesquisador se mune, dá-se na realização do questionamento, resultado daquilo que Foucault (2000) chama de ruptura, gerando novas informações. Para que essa ruptura seja relevante, é certo que o pesquisador precisa ter de forma clara aquilo que busca e que aos seus questionamentos sejam cabíveis respostas reais nos moldes científicos. Os desafios da ciência não devem desviar o pesquisador. Para Bourdieu (1989), pesquisar é procurar, indagar, questionar 0 mundo, principalmente aquele que rodeia 0 pesquisador.

Dessa maneira, mesmo diante da atual difusão e aplicação da netnografia como metodologia de pesquisa etnográfica das ciberculturas, faz-se necessário tratar tal metodologia de pesquisa como objeto de estudo, questionando suas bases e pressupostos, de forma a avançar na sua compreensão. Assim, este trabalho tem como objetivo analisar a evolução das pesquisas em netnografia, a partir da aplicação de uma análise bibliométrica nas produções científicas que utilizaram ou que tratam sobre o método. Para essa análise, optou-se pela utilização da base de dados Web of Science ${ }^{T M}$, principalmente pela sua abrangência ao conter inúmeras áreas científicas. Espera-se que este estudo possa contribuir com uma caracterização geral dos trabalhos já desenvolvidos acerca da metodologia netnográfica, bem como das pesquisas nas quais tal metodologia foi aplicada. Desse modo, se expressa a relevância deste 
estudo ao permitir uma reflexão acerca da própria netnografia e a proposição de uma agenda de pesquisas que favoreçam o seu desenvolvimento.

\section{Do espaço ao ciberespaço}

Segundo Angrosino (2009), a palavra etnografia significa, literalmente, a descrição de um povo. Requer, talvez mais do que em outras ciências, o relato honesto de todos os dados e, só terá valor científico irrefutável se permitir distinguir claramente, de um lado, os resultados da observação direta e das declarações e interpretações nativa e, de outro, as inferências do autor, baseadas em seu próprio bom senso e intuição psicológica (MALINOWSKI, 1978). Geertz (2001, p. 20) a descreve da seguinte forma:

Fazer etnografia é como tentar ler (no sentido de construir uma leitura de) um manuscrito estranho, desbotado, cheio de elipses, incoerências, emendas suspeitas e comentários tendenciosos, escrito não com os sinais convencionais do som, mas com exemplos transitórios de comportamento modelado.

Berço da civilização ocidental, a Grécia antiga nos legou um dos primeiros tratados etnográficos conhecidos, a descrição feita por Heródoto sobre "os costumes, as vestimentas, as armas, os barcos, os tabus alimentares e as cerimônias religiosas dos persas e povos circunvizinhos" (GOLDENBERG, 2004, p. 16). Já a etnografia moderna foi proposta por Malinowski (1978), na obra seminal "Argonautas do Pacífico Ocidental", na qual se pode observar com clareza o fazer etnografia. "Imagine-se o leitor sozinho, rodeado apenas de seu equipamento, numa praia tropical próxima a uma aldeia nativa, vendo a lancha ou o barco que o trouxe afastar-se no mar até desaparecer de vista" (MALINOWSKI, 1978, p. 19). Pode-se imaginar com exatidão o cenário, a aldeia, o material, a lancha ou o barco e, além da imaginação, pode-se acertar que os mesmos foram reais.

Com o advento de novas tecnologias e a disseminação da internet, está sendo proposta uma nova metodologia para pesquisas na área de gestão, a netnografia, como uma forma especializada de etnografia adaptada às contingências específicas dos mundos sociais de hoje mediados pela tecnologia (KOZINETS, 2014). Em uma analogia com a citação supra, uma aldeia nativa se transforma em um campo virtual, o material em um software e a lancha ou barco no que o internauta quiser.

Como processo, a netnografia é uma "metodologia de pesquisa qualitativa que se adapta a novas técnicas de pesquisa etnográfica para o estudo das culturas e comunidades que estão surgindo através da comunicação mediada por computador" (KOZINETS, 2014, p. 62). Como um produto, é "um relato através de textos escritos, imagens, sons e vídeos da cibercultura online, que informa através dos métodos da antropologia cultural" (KOZINETS, 2014, p. 62). 
A netnografia vem cada vez mais utilizada por pesquisadores das áreas da comunicação, marketing, antropologia e sociologia, principalmente, segundo Rutter e Smith (2005), pela comodidade que ela traz ao permitir que o acesso aos dados das comunidades e culturas virtuais ocorra dentro dos próprios escritórios dos pesquisadores, facilitando ainda a gravação e arquivamento desses dados para análises posteriores. Em complemento, Rocha e Montardo (2005) destacam sua importância diante da necessidade de explorar características específicas da sociedade contemporânea, como a virtualidade, desmaterialização e digitalização de relacionamentos, produtos, formas e conteúdos, que fazem parte do contexto da cibercultura, sendo a netnografia uma ferramenta metodológica de acesso dos pesquisadores a esse campo.

Sendo a cibercultura uma cultura fundamentada na tecnologia e formada a partir da interação da sociedade com o ambiente virtual (LEMOS; VALENTIM, 2006) e este ambiente virtual, o ciberespaço, um novo ambiente para a ocorrência das dinâmicas de comunicação e socialização da informação e do conhecimento (LÉVY, 2007), a netnografia tem ainda como propósito permitir a exploração das novas linguagens e signos criados na comunicação mediada por computador, sendo denominada por Freitas e Leão (2012) de netnografia da comunicação.

Apesar de tais benefícios e possibilidades de aplicação, deve-se ater ao cuidado de que uma aceitação da netnografia como método, sem contestação, pode apontar para a subalternidade e a colonialidade do saber. Assim, contestar a aplicabilidade da netnografia como método de pesquisa, bem como avaliar seus critérios de confiabilidade e validade e a (im)possibilidade de triangulação também são pontos relevantes, principalmente diante das limitações do método, como expressas por Hsing e Souza (2013).

Em relação à confiabilidade, por exemplo, Laperrière (2012) aponta que esta requer aplicabilidade extensiva das análises no tempo e no espaço, o que é corroborado por Gaskell e Bauer (2002, p. 482) quando indicam que "os resultados da investigação representam a realidade e são mais do que produto da imaginação fértil do pesquisador". Quanto à validade, deve-se observar essencialmente a exatidão e pertinência da ligação estabelecida, utilizando-se uma metodologia adequada, entre as observações empíricas e o sentido da interpretação (LAPERRIÈRE, 2012). No caso, porém, da netnografia, não há a possibilidade de comparar representação e ação, ou seja, as falas com o comportamento real, como ocorre na etnografia: "Neste aspecto, a netnografia sozinha não tem este poder se o objetivo do estudo inclui entender o comportamento fora da internet" (HSING; SOUZA, 2013, p. 7). Seus limites, portanto, se configuram apenas na realidade dentro do ambiente virtual.

Além disso, pode-se ainda considerar que o neologismo netnografia não seja adequado como método de pesquisa, pois o ambiente virtual é um não-lugar, isto é, "espaços que não são em si lugares antropológicos" (AUGÉ, 1994, p.73), desterritorializado e de não pertencimento físico e presencial do lugar. Neste sentido, há incoerência epistemológica entre o 
termo netnografia e a prática da pesquisa assim nomeada, pois como ensina Levi-Strauss (1991), o caráter distintivo do objeto de estudo da antropologia é a experiência de campo. Sem o campo, os conhecimentos serão descontínuos, jamais formarão um todo.

Assim, reconhece-se que netnografia como método de pesquisa, recente e adaptado da etnografia, ainda não encontrou seu consenso entre pesquisadores. Alguns estudos, portanto, têm sido desenvolvidos no sentido de identificar seus principais contextos de aplicação e utilização em pesquisas, tratando o referido método como objeto de estudo.

Neste sentido, Rocha e Montardo (2005) denotam a importância da netnografia pela sua presença em pesquisas das mais diversas áreas, como a antropologia, sociologia e comunicação, principalmente por pesquisadores de língua inglesa, e ainda no planejamento de marketing de grandes empresas.

Destacando as diferenças entre a etnografia e a netnografia, principalmente no que diz respeito aos limites desta última em possibilitar a observação apenas do aspecto comunicacional da comunidade, Amaral, Natal e Viana (2008) indicam alguns procedimentos netnográficos para a utilização de games, chats e plataforma sociais nas pesquisas em ciberculturas, como os sugeridos por Kozinets (2014), de entrée cultural, coleta e análise dos dados, ética de pesquisa e, por fim, feedback e checagem de informações com os membros do grupo.

Quanto aos temas relacionados aos trabalhos netnográficos, Sandlin (2007) aponta uma variedade considerável nas pesquisas já desenvolvidas como, por exemplo: casamentos entre culturas; novos movimentos sociais de ativismo consumidor; organizações de direitos humanos; comunidades online de café; fãs de séries de tv; e até consumo de nostalgia por meio de marcas retros. Já Noveli (2010) encontrou trabalhos que incluem temas como cirurgia cosmética, negociação de significados de consumidores de revistas e usuários de bibliotecas digitais.

Em relação aos trabalhos bibliométricos desenvolvidos no campo, denota-se apenas o de Hsing e Souza (2013) que apresentam breve pesquisa realizada no banco de dados Web of Science, em março de 2013, em que foram encontrados 52 artigos que utilizaram a netnografia em suas pesquisas. Para os trabalhos que visavam o estudo das ações dos indivíduos fora do ambiente virtual, foram comumente aplicadas técnicas interativas adicionais com entrevistas, tendo em vista confirmar os resultados encontrados pela netnografia.

\section{Procedimentos metodológicos}

Conforme apontam Minayo e Sanches (1993), a escolha do método deve ter como foco a possibilidade de reflexão sobre a dinâmica da teoria a partir da correta construção dos dados. Para tanto, tendo como objetivo analisar a evolução das pesquisas em netnografia nas produções científicas na área, optou-se pela realização de uma pesquisa biliométrica, cuja importância têm sido bastante ressaltada por autores como Diem e 
Wolter (2013) e Miguel e Dimitri (2013). Primeiramente foi definida por Pritchard (1969, p. 349) como "a aplicação de matemática e métodos estatísticos para livros e outros meios de comunicação", em substituição ao termo bibliografia estatística, utilizado até então, mas considerado confuso pelo autor por não representar o real escopo deste tipo de pesquisa. Sua utilização, conforme Raisig (1962), tem como intuito a investigação de um determinado campo da ciência a partir de sua evolução histórica, produção nacional e internacional de livros e artigos ou mesmo a sua utilização.

Os procedimentos para a análise bibliométrica seguem três etapas propostas por Santos, Kalsing e Hansen (2014): a escolha da base de dados e os critérios a serem utilizados para a coleta; a própria coleta de dados; e a representação e análise dos dados. No emprego da bibliometria, Koskinen et al. (2008) ressaltam a importância na seleção da base de dados a ser utilizada, mantendo-se sempre a imparcialidade dessa escolha com o objetivo da pesquisa. Dessa forma, foi escolhida como base de dados a ISI Web of Knowledge/Web of Science (Web of Science - SSCI Social Sciences Citation Index), considerada por Santos, Maldonado e Santos (2011) como uma das mais abrangentes bases de periódicos, formada por inúmeras áreas científicas.

Em relação aos critérios de seleção, foram utilizadas as palavras netnograph* e netnografia como termos de busca dos artigos, tanto nos títulos, como nos resumos, palavras-chave do autor e palavras-chave criadas (keywords plus). Essa busca foi realizada em todo o período disponível na base de dados para artigos completos (1945-2015), possibilitando a replicação ou atualização desta pesquisa sem a necessidade de realizá-la novamente desde o início. Em um segundo momento, foi feito ainda o refinamento dos trabalhos encontrados por meio da aplicação de filtro oferecido pelo mecanismo de busca da coleção principal da Web of Science selecionando-se o tipo de documento article, de forma que os resultados apresentassem apenas trabalhos completos publicados em periódicos, excluindo-se capítulos de livro, resenhas e artigos em eventos (proceeding papers). Além disso, foram filtradas as áreas comuns à gestão: "business", "management", "economics" and "business finances". Assim, foram identificados 105 artigos para integrar o conjunto final de trabalhos analisados bibliometricamente nesta pesquisa.

Tendo em vista a organização dos artigos coletados para análise, realizou-se uma marcação dos seguintes elementos nos textos dos artigos: título; ano de publicação; autores (quantidade por artigo e nomes); instituições; países de origem; periódico; referências. Assim, tais elementos foram agrupados, ordenados e organizados para a realização da análise bibliométrica, a partir da exportação destes dados para o pacote de software de análise bibliométrica HistCite ${ }^{\mathrm{TM}}$. Com o auxílio do software foram analisados aspectos como: a evolução anual da quantidade de publicações; os periódicos e os autores com maior quantidade de artigos na área; a quantidade de artigos distribuídas por país de origem dos autores; os artigos mais citados na Web of Science 
(global) e aqueles mais citados no conjunto de artigos selecionados (local). Além destes dados gerados pelo software, foram elucidados aspectos dos textos dos dez artigos mais citados globalmente e dos dez artigos mais citados localmente no intuito de identificar suas principais contribuições para a temática da netnografia.

\section{Apresentação e análise dos resultados}

Após realizado o levantamento bibliométrico na principal coleção do Web of Science ${ }^{\mathrm{tm}}$ foram identificados 105 artigos sobre netnografia. Estes artigos estão publicados em 45 periódicos distintos indexados à base de dados em questão e foram escritos por 210 autores que possuem vínculos à 140 instituições localizadas em 31 países. O Brasil não aparece como país onde artigos sobre netnografia são produzidos e publicados, o que pode indicar ausência destes estudos ou apenas sua falta nesta base de dados. Para a consecução destes artigos foram utilizadas 4.904 referências, com uma média de aproximadamente 47 referências por artigo. Na Tabela 1, a seguir, são apresentados esses resultados.

Tabela 1 - Resultados Gerais do Levantamento Bibliométrico sobre Netnografia (1997-2015)

\begin{tabular}{lc}
\hline Dados Bibliométricos & Quantidade \\
\hline \hline Publicações (artigos) & 105 \\
Periódicos indexados & 45 \\
Autores & 210 \\
Instituições (vínculos dos autores) & 140 \\
Países & 31 \\
Referências citadas & 4.904 \\
\hline
\end{tabular}

Fonte: Elaboração própria a partir de dados da Web of Science.

Conforme é possível observar na Figura 1, a seguir, que apresenta a evolução das publicações nesta temática, o primeiro registro de artigo indexado na Web of Science ${ }^{\mathrm{tm}}$ data do ano de 1997. Este trabalho de autoria de Kozinets (1997) cunha o termo "netnografia" pela primeira vez e demonstra seu "débito" ao revisor anônimo que o sugeriu para o autor, conceituando o método como um relato escrito de uma cibercultura online a partir dos métodos da antropologia cultural. $O$ autor refere-se à cibercultura como a cultura mediada pelas tecnologias de informação e comunicação contemporâneas. Os trabalhos seguintes, dos anos de 1998 a 2002 também são de autoria de Kozinets (KOZINETS, 1998; KOZINETS; HANDELMAN, 1998; KOZINETS, 2002), com registros de outros autores aparecendo no ano de 2003, seis anos após ele ter lançado o termo e o primeiro estudo netnográfico. 
Figura 1 - Distribuição anual das publicações sobre netnografia (19972015)

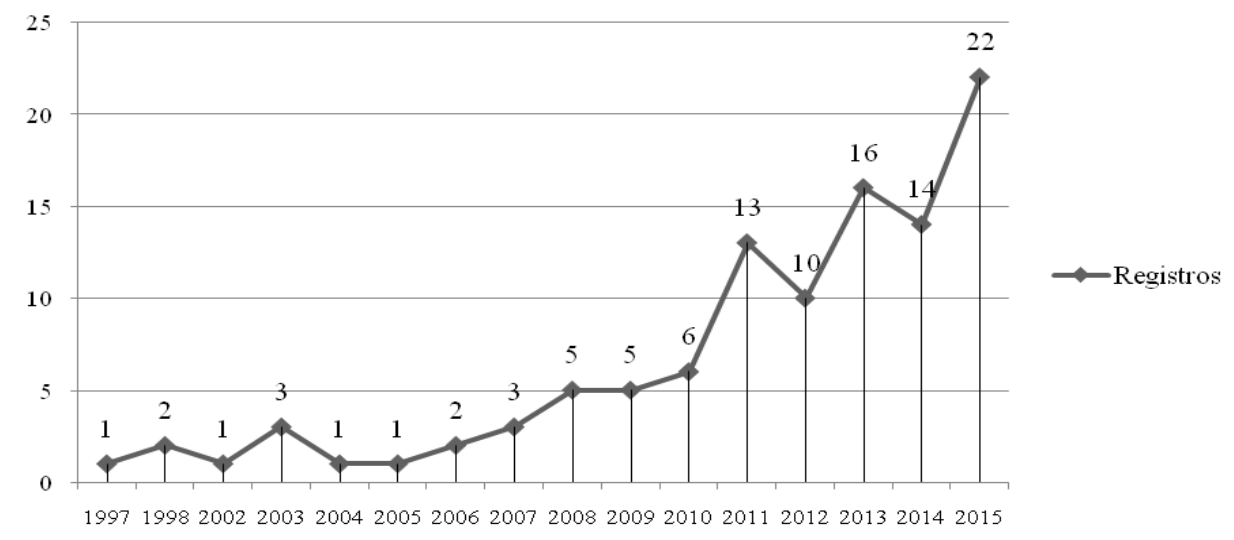

Fonte: Elaboração própria a partir de dados da Web of Science.

Até o início da década de 2000 nenhum outro autor havia publicado artigos sobre netnografia. Foi em 2003 que Giesler e Pohlmann (2003a; 2003b) investigaram uma forma de emancipação social a partir do uso do serviço on-line de compartilhamento de arquivos de músicas Napster. Os autores descrevem sua metodologia como uma "análise netnográfica exploratória" citando Kozinets e fazendo menção às suas sugestões de procedimentos. Apesar de não apresentar um crescimento ininterrupto, 0 número de estudos que tratam da netnografia continua crescente e 2015 foi o ano em que estes resultados apresentaram seu ápice, destacando a atualidade e relevância do tema.

Tabela 2 - Top 10 Periódicos com mais artigos publicados sobre Netnografia (1997-2015)

\begin{tabular}{|c|c|c|c|c|}
\hline Periódicos & & $\begin{array}{l}\text { Quantidade } \\
\text { de Artigos }\end{array}$ & Citações & $\begin{array}{l}\text { Citações/ } \\
\text { Quantidade }\end{array}$ \\
\hline Journal of Business Research & & 14 & 366 & 26,14 \\
\hline Tourism Management & & 8 & 78 & 9,75 \\
\hline European Journal of Marketing & & 6 & 127 & 21,17 \\
\hline Consumption Markets \& Culture & & 5 & 15 & 3 \\
\hline Management Decision & & 5 & 20 & 4 \\
\hline International Journal of Consumer Studies & & 4 & 26 & 6,5 \\
\hline Journal of Consumer Behavior & & 4 & 17 & 4,25 \\
\hline $\begin{array}{l}\text { International Journal of Contemporary } \\
\text { Management }\end{array}$ & Hospitality & 3 & 31 & 10,3 \\
\hline International Journal of Market Research & & 3 & 8 & 2,7 \\
\hline Marketing Theory & & 3 & 20 & 6,7 \\
\hline
\end{tabular}
Fonte: Elaboração própria a partir de dados da Web of Science.

A Tabela 2 identifica os periódicos internacionais mais representativos para a temática da netnografia. Foram analisados os 45 periódicos indexados na Web of Science ${ }^{t m}$ em relação à quantidade de artigos publicados sobre o tema e o total de citações na base de dados e separados os dez primeiros com maior quantidade de registros de publicação. Ao somar os trabalhos publicados nestes dez periódicos 
resultou-se num total de 55 registros, o que corresponde a $52,4 \%$ da quantidade total de trabalhos identificados. O periódico com maior número de publicações é o Journal of Business Research com 14 artigos. A fim de identificar aqueles periódicos com maior representatividade, calculamos um índice em que é possível verificar a relação entre o número de citações e o número de artigos publicados em cada um deles. A partir deste índice pode-se perceber o impacto dos artigos identificados nestes periódicos sob o total de citações recebidas dentro da base de dados em questão. Desta forma, fica evidente que o periódico com maior índice citações/artigo também é o Journal of Business Research. Este índice pode ser útil para futuras pesquisas e funcionar como um indicador da relevância dos periódicos com mais publicações sobre o assunto. Cabe também 0 destaque ao European Journal of Marketing com índice semelhante ao anterior. É perceptível a predominância de periódicos da área de marketing no grupo apresentado na Tabela 2. Isso indica a prevalência de estudos que usam ou tratam da netnografia em campos como comportamento do consumidor, teoria de marketing, cultura, turismo e pesquisa de marketing em geral.

Tabela 3 - Autores com maior número de publicações em netnografia (1997-2015)

\begin{tabular}{|c|c|c|c|}
\hline Autores & $\begin{array}{l}\text { Quantidade } \\
\text { de Artigos }\end{array}$ & Afiliação (Instituição de vínculo) & País \\
\hline $\begin{array}{l}\text { Kozinets, R. } \\
\text { V. }\end{array}$ & 6 & $\begin{array}{c}\text { Annenberg School for Communication } \\
\text { and Journalism }\end{array}$ & Estados Unidos \\
\hline Janta, H. & 4 & University of Surrey & Reino Unido \\
\hline Adjei, M. T. & 3 & Southern Illinois University Carbondale & Estados Unidos \\
\hline Lugosi, P. & 3 & $\begin{array}{c}\text { Oxford School of Hospitality } \\
\text { Management }\end{array}$ & Reino Unido \\
\hline Rokka, J. & 3 & EMLYON Business School & França \\
\hline Chan, K. W. & 2 & Hong Kong Polytechnic University & $\begin{array}{l}\text { República Popular da } \\
\text { China }\end{array}$ \\
\hline $\begin{array}{l}\text { Corciolani, } \\
\text { M. }\end{array}$ & 2 & Università di Pisa & Itália \\
\hline Cova, B. & 2 & KEDGE Business School & França \\
\hline Dehuang, N. & 2 & $\begin{array}{c}\text { Kunming University of Science and } \\
\text { Technology }\end{array}$ & China \\
\hline Ertimur, B & 2 & Silberman College of Business & Canadá \\
\hline
\end{tabular}

Fonte: Elaboração própria a partir de dados da Web of Science.

Após análise dos periódicos foram identificados os autores que possuem maior quantidade de registros de publicações na seleção deste estudo bibliométrico. A Tabela 3 apresenta a listagem com o nome desses autores, o seu vínculo institucional (instituição de vínculo) e país de origem da instituição. Foram selecionados os dez autores com maior quantidade de registros. Entre os autores com mais publicações sobre 0 tema estão Robert V. Kozinets da Annenberg School for Communication and Journalism (Estados Unidos), e Hania Janta, que atualmente trabalha na University of Surrey (Reino Unido). A partir da observação da Tabela 3 
também é possível verificar que a maior quantidade de trabalhos tem origem nos Estados Unidos e em países europeus, com destaque para 0 Reino Unido e França.

Tabela 4 - Quantidade de artigos por país de origem das instituições de vínculo dos autores

\begin{tabular}{lc}
\hline País & Quantidade \\
\hline \hline Estados Unidos da América & 28 \\
Reino Unido & 13 \\
Austrália & 12 \\
País desconhecido (ou não informado) & 8 \\
China & 7 \\
Suécia & 6 \\
Finlândia & 5 \\
Canadá & 4 \\
Dinamarca & 4 \\
França & 4 \\
\hline Fonte: Elaboração própria a partir de dados da Web of Science.
\end{tabular}

Para visualizar a representatividade dos países de origem das instituições de vínculo dos 210 autores dos 105 trabalhos mapeados neste estudo bibliométrico foram identificados os dez países com mais produção científica no campo da netnografia, que podem ser observados na Tabela 4. Os Estados Unidos lideram o ranking, acompanhado por países europeus, Austrália, China e Canadá.

Dentre o conjunto de 105 artigos localizados na base Web of Science ${ }^{T M}$ buscou-se identificar os trabalhos mais representativos sobre 0 tema. Para isso, foram identificados dois grupos de artigos: (i) artigos que receberam mais citações de outros trabalhos em toda a base de dados e (ii) artigos que receberam mais citações dos trabalhos do grupo de seleção deste estudo bibliométrico. A Figura 2, a seguir, apresenta a relação entre os artigos mais citados dos dois grupos, indicando, dentre estes, quais apresentam conexão de citações (linhas que conectam os círculos) e quais são os mais citados no grupo (tamanhos diferentes dos círculos). 
Figura 2 - Top 10 artigos mais citados na Web of Science ${ }^{T M}$ (Global Citation Score) e Top 10 artigos mais citados no grupo de artigos selecionados (Local Citation Score) dentre o conjunto selecionado
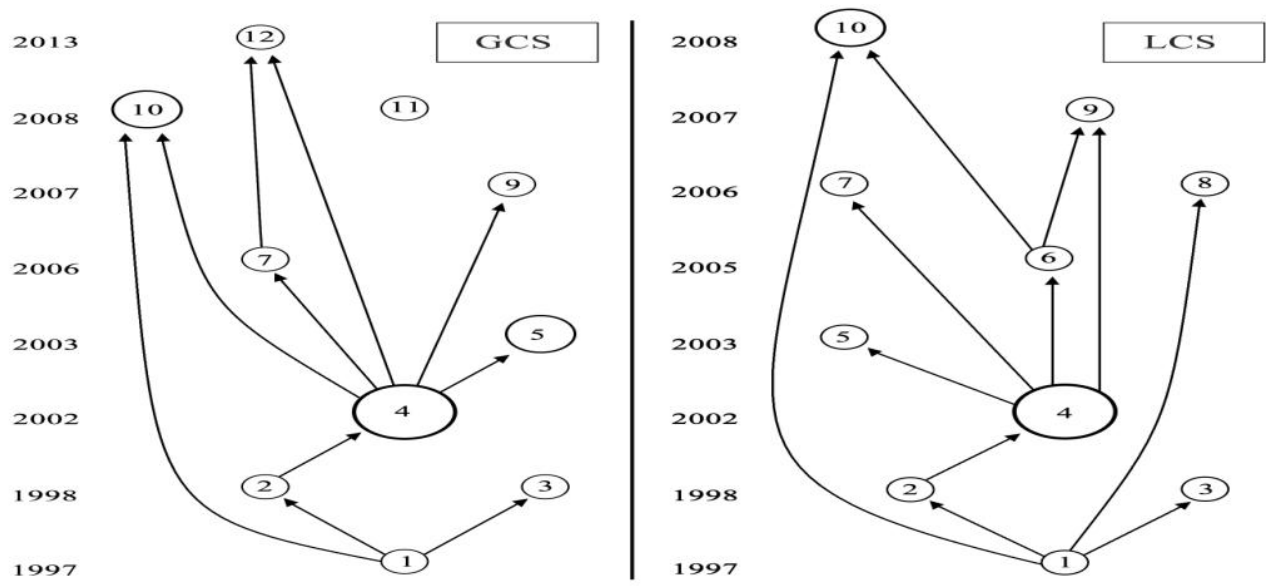

Legenda:

GCS - Global Citation Score (Top 10 artigos sobre a temática que receberam maior quantidade de citações no Web of Science ${ }^{\mathrm{TM}}$ )

LCS - Local Citation Score (Top 10 artigos sobre a temática que receberam maior quantidade de citações dos artigos selecionados)

1- Kozinets (1997)

2- Kozinets (1998)

3- Kozinets e Handelman (1998)

4- Kozinets (2002)

5- Brown, Kozinets e Sherry (2003)

6- Nelson e Otnes (2005)

Fonte: Elaboração própria a partir de dados da Web of Science.

\author{
7- Cova e Pace (2006) \\ 8 - Kozinets (2006) \\ 9- Fuller, Jawecki e Muhlbacher (2007) \\ 10- Mathwick, Wiertz e de Ruyter (2008) \\ 11- Yim, Tse e Chan (2008) \\ 12- Brodie et al. (2013)
}

O primeiro trabalho, em ordem cronológica de publicação, foi publicado por Kozinets (1997). Referência seminal nos estudos sobre o método netnográfico, apesar de não ser o trabalho mais citado do autor, o uso do termo "netnografia" foi incluído no texto após sugestão de um avaliador anônimo do periódico em que foi publicado e, como o autor descreve: "a netnografia como um tipo de pesquisa é muito nova e, portanto, possui poucas orientações". A sequência da descrição do método utilizado no trabalho indica que, por este motivo, ela está sujeita a muitas das mesmas preocupações de validade e avaliações que as modalidades de pesquisa qualitativa.

Apesar da novidade do método, esta situação não é considerada nas conclusões ou mesmo numa descrição mais densa de suas escolhas metodológicas. $O$ autor não justifica sua posição neste sentido e toma por certo o uso da netnografia como método sem uma discussão metodológica específica, explicando a ampliação do escopo dos estudos sobre cultura de consumo ao campo das relações virtuais como principal motivo para a situação empírica do seu trabalho.

Em 1998, ano seguinte, os dois únicos trabalhos sobre o tema ainda são de autoria do mesmo autor. Em Kozinets (1998) o autor endereça debate sobre o método da netnografia julgando-a uma adaptação de 
pesquisa às mudanças contemporâneas da sociedade, dentre as muitas adaptações em curso que pesquisadores estão desenvolvendo de modo a acompanhar a compreensão do comportamento do consumidor que ocorre na ou é afetado pela internet. Neste sentido, o autor informa que a netnografia é uma adaptação de métodos qualitativos utilizados na pesquisa sobre o consumidor, antropologia cultural e estudos culturais situados no comportamento do consumidor de comunidades virtuais e ciberculturas.

Neste trabalho, há uma preocupação exclusiva com o método, suas origens e possibilidades. Há descrições de formas de coleta de dados, emprestadas do método etnográfico, com a adição dos registros on-line às anotações, entrevistas, fotografias e arquivos de áudio. Além disso, há indicação de uso da netnografia especialmente direcionada às pesquisas sobre consumo. Contudo, o autor sugere que seu uso pode abarcar, principalmente, três tópicos: como uma metodologia para o estudo de ciberculturas e comunidades virtuais; como uma ferramenta para coleta de dados para o estudo de ciberculturas e comunidades virtuais; e uma ferramenta exploratória para pesquisar tópicos gerais.

Em comparação à etnografia clássica, a netnografia apresenta como vantagens a possibilidade da proximidade virtual, excluindo-se as longas distâncias geográficas viajadas e a disponibilidade de tempo longe do ambiente doméstico. Entretanto, o netnógrafo depara-se com o obstáculo de não encontrar-se pessoalmente com o grupo investigado, tendo sua comunicação mediada pelo computador, o que pode gerar problemas de validade. Kozinets (1998) sugere que haja vigilância para a solução deste óbice. No seu outro trabalho no mesmo ano de 1998, em parceria com outro autor, Kozinets e Handelman (1998) discutem o comportamento de boicote do consumidor virtual utilizando-se de uma metodologia netnográfica interpretativa, dada a natureza exploratória do estudo. Além de citar o conceito já apresentado no seu trabalho anterior, não há nova discussão metodológica ou consideração a respeito do uso desta metodologia.

O trabalho de Kozinets (2002) foi o mais citado nos dois grupos identificados, recebendo 494 citações na Web of Science ${ }^{T M}$ e 73 citações do grupo dos 105 artigos selecionados para este estudo. Este artigo pode ser considerado "artigo autoridade" ou "artigo base" (SANTOS et al., 2014), pois é referência principal de outros que também recebem grande quantidade de citações. Em comparação, a soma das citações dos seus três trabalhos anteriores gera o resultado de 222 citações na Web of Science ${ }^{T M}$ e 48 citações no grupo dos artigos analisados. O início do texto é marcado pela seguinte citação:

O autor desenvolve 'netnografia' como uma técnica de pesquisa online de marketing para verificar a percepção do consumidor. 'Netnografia' é a etnografia adaptada ao estudo de comunidades online. Como método, a 'netnografia' é mais rápida, mais simples e menos cara que a etnografia tradicional, além de mais naturalista e comedida do que grupos de foco ou entrevistas. Ela fornece 
informações sobre o simbolismo, significados e padrões de consumo dos grupos de consumidores on-line. O autor fornece diretrizes que se adéquam ao ambiente on-line, $o$ respeito à flexibilidade $e$ abertura inerentes à etnografia, e fornece rigor e ética na condução de pesquisas de marketing (KOZINETS, 2002, p. 1, tradução nossa).

O texto de Kozinets (2002) é marcado por uma discussão mais profunda que os anteriores, iniciando pela própria afirmação de realidade das comunidades virtuais, entrando num jogo de palavras entre o que é ou não virtual e real. Discussão curta, mas semelhante àquela proposta por Lévy (2007), quando diz que o virtual existe - apesar de ser para o autor algo não real - não em matéria, pois esta subexiste em substância, mas é atualizado pela tecnologia de informação ao qual é associada. Em continuação, o autor retrata a crescente importância das comunidades virtuais nas discussões de marketing, especialmente as que se organizam em torno de objetivos comuns como esporte, música, comida, filmes e outros.

O texto também é marcado por uma possível crítica do próprio uso indiscriminado do termo "netnografia", quando desta vez o autor insere logo em seguida ao seu uso: "ou etnografia na internet" (KOZINETS, 2002 , p. 2). Além de repetir algumas das discussões de seu artigo anterior (KOZINETS, 1998), o autor acrescenta informações sobre as diretrizes para se proceder com uma netnografia, pois o pesquisador deve: primeiro, ter uma pergunta de pesquisa direcionada ao campo do marketing e, segundo, aprender sobre ferramentas de comunicação online. Além deste primeiro passo, chamado de "entrée", há outros quatro nomeados, em ordem, coleta e análise dos dados, interpretação confiável, garantia de ética na pesquisa e oferecimento de feedback para a comunidade investigada. O texto trata de um guia que discute os passos para execução de uma netnografia apresentando um exemplo de aplicação ao final.

Em sequência, agora em companhia de outros autores, Brown, Kozinets e Sherry Jr (2003, p. 22) realizam "em consonância com o espírito retrospectivo do estudo", uma "investigação empírica que utiliza uma técnica de pesquisa nova à moda antiga chamada 'netnografia'" sobre marcas retrô - tratando especificamente de relançamento de produtos. Ainda sem utilizar outras referências, seu nome (KOZINETS, 2002) é o único que aparece em citações sobre o método.

Além da figura do artigo autoridade aqui assumindo o Kozinets (2002) também aparecem os artigos "hub", ou artigos de ligação (SANTOS et al., 2014): os trabalhos de Nelson e Otnes (2005) e Cova e Pace (2006). Nelson e Otnes (2005) estudaram como a ambivalência cross-cultural influencia noivas enquanto elas planejam seus casamentos com noivos de outras culturas. As autoras repetem o cuidado de Kozinets (2002), inclusive citando-o, enquanto informam que fizeram uma "análise etnográfica de mensagens publicadas on-line" identificando esta análise logo em seguida entre parenteses "(netnografia)" e empregaram uma nova modalidade de pesquisa qualitativa "chamada netnografia ou 
'etnografia na internet'". Além destas menções, não há qualquer outro debate ou informação sobre o método. Cova e Pace (2006), em seu estudo, utilizaram diversos métodos de coleta de dados: entrevistas, análises de documentos e netnografia para analisar o poder que uma comunidade virtual de marca exerce sobre a marca de um produto comercializado em massa. Os autores também citam Kozinets (2002) para a definição e descrição do método de pesquisa, nomeando-o da mesma forma que Nelson e Otnes (2005).

Ao retornar à lista cronológica dos mais citados, Kozinets (2006) volta sua atenção ao trabalho dos redatores de publicidade, informando que a netnografia é uma forma rápida, oportuna e barata de se obter informações válidas sobre grupos de consumidores. Neste artigo o autor inclui a sentença "a prática on-line da antropologia" à sua definição do método e revisa as questões éticas e de qualidade do uso da netnografia já apresentadas em trabalho prévio (KOZINETS, 2002), indicando que estas devem ser as preocupações dos pesquisadores ao adentrarem as interpretações de dados empíricos on-line.

O trabalho de Fuller, Jawecki e Muhlbacher (2007) teve como objetivo analisar as atividades de inovação em comunidades online de consumidores de tênis para basquete. Eles utilizam a netnografia como método para conhecer como as comunidades online de usuários contribuem para a qualidade e a variedade de inovações e quais os aspectos culturais que motivam os usuários a participarem destas atividades. Os autores destacam a importância da netnografia no conhecimento acerca deste tipo de comunidade virtual, as comunidades de usuários, e sua atuação no desenvolvimento de inovações em que o usuário é uma fonte de inovação importante. A netnografia, neste caso, é apontada como método ideal para o conhecimento do processo de inovação dirigido pelos usuários. Este é o primeiro artigo do grupo que usa outra referência, além de Kozinets (2002) para apresentar a netnografia como um método (NELSON; OTNES, 2005).

O texto de Mathwick, Wiertz e Ruyter (2008) objetivou analisar as normas sociais que fundamentam a formação de capital social, no que diz respeito às interações dos agentes em uma rede. Os autores investigam a formação do capital social em uma comunidade virtual criada para a resolução de problemas peer-to-peer de consumidores relacionados às experiências de consumo compartilhado. Além da netnografia, foram utilizados questionário para coleta de informações demográficas sobre os participantes da comunidade e tempo de participação na comunidade. Eles citam Kozinets $(1997 ;$ 2002) na apresentação do método de netnografia e como exemplos de pesquisa com comunidades, acrescentando Nelson e Otnes (2005) também como exemplo.

Yim, Tse e Chan (2008) investigam a afeição entre os consumidores e as empresas a partir de elementos de satisfação, confiança e lealdade. Além da netnografia, os autores também utilizam questionário para coleta de informações com consumidores do mundo real para confirmar os achados. Estes autores não citam nenhum outro trabalho para 
exemplificar ou apresentar o método netnográfico, apenas informando que fizeram uma netnografia.

Brodie et al. (2013), o trabalho mais recente dos grupos de mais citados, tiveram como objetivo explorar a natureza eo alcance da participação do consumidor em um ambiente de comunidade de marca online. Eles utilizam a netnografia como método em uma comunidade online de uma empresa da área fitness, avaliando a participação dos consumidores na comunidade da empresa e seu engajamento, criando um modelo deste engajamento em comunidades online. A netnografia é utilizada para avaliar a quantidade e tamanho dos comentários e postagens dos participantes e construir um modelo para o tema. Neste sentido, citam Kozinets (1997) para definição de netnografia e Kozinets (2002) para apresentação do método. Cova e Pace (2006) aparecem como exemplo de pesquisa sobre empoderamento de consumidores.

\section{Considerações finais}

O trabalhado é concluído após mapear as produções mais relevantes sobre netnografia em uma das principais bases de dados acadêmicos mundiais. Esta situação das pesquisas netnográficas, sejam elas empíricas ou discussões metodológicas, é marcada por uma prevalência de área temática - estudos de marketing - e referências a um autor. Além disso, há pouca evolução em debate sobre o uso indiscriminado do termo e da metologia netnográfica, visto que as referências fazem menção apenas ao trabalho seminal de Kozinets ou seus trabalhos em anos seguintes.

Considerando que o principal trabalho, em número de citações, sobre netnografia seja um guia do próprio autor que se apropriou do termo ao usá-lo pela primeira vez, este trabalho sugere, além de outras implicações para pesquisa, investigações metodológicas que discutam as características desta técnica que surgiu a partir de pesquisas no campo do comportamento do consumidor, mas que possui raízes na antropologia cultural com sua metodologia-mãe etnografia. Neste sentido, há aspectos empíricos não explorados na literatura, como o (i) posicionamento de especialistas do campo antropológico sobre a adaptação de método, (ii) o uso da técnica em outras áreas do conhecimento, visto que ela é majoritariamente utilizada no marketing e (iii) as possibilidades de evolução em consonância ao desenvolvimento das tecnologias de informação e comunicação.

Além destas sugestões, outras podem ser acrescentadas no intuito de enriquecer 0 arsenal do pesquisador que questione 0 uso da netnografia e suas implicações para os estudos das organizações ou aquele que queria fazer uso da técnica. Como este trabalho foi restrito à base de dados Web of Science ${ }^{T M}$, sugere-se que: (i) sejam realizadas outros estudos bibliométricos em outras bases de dados, (ii) investigações sobre produções nesta temática em eventos e periódicos exclusivamente brasileiros, dados os resultados deste trabalho não apresentarem registros nacionais indexados, e (iii) ensaios metodológicos que discutam aspectos 
não evidentes nas leituras dos textos já publicados, como a apropriação de um campo empírico tão particular e subjetivo como a internet e as redes sociais sem aprofundar o debate do seu uso como lócus de investigação.

\section{Referências}

AMARAL, A.; NATAL, G.; VIANA, L. Netnografia como aporte metodológico da pesquisa em comunicação digital. Cadernos da Escola de Comunicação, v. 6, p. 1-12, 2008.

ANGROSINO, M. Etnografia e observação participante. Porto Alegre: Artmed, 2009.

AUGÉ, M. Não-lugares: introdução a uma antropologia da supermodernidade. 3. ed. Campinas, SP: Papirus, 1994.

BOURDIEU, P. Introdução a uma sociologia reflexiva. Lisboa: Difel, 1989.

BRODIE, R. J. et al. Consumer engagement in a virtual brand community: an exploratory analysis. Journal of Business Research, v. 66, n. 1, p. 105$114,2013$.

BROWN, S.; KOZINETS, R. V.; SHERRY JR, J. F. Teaching old brands new tricks: retro branding and the revival of brand meaning. Journal of Marketing, v. 67, n. 3, p. 19-33, 2003.

CAVEDON, N. R. Antropologia para administradores. Porto Alegre: Editora da UFRGS, 2003.

COVA, B.; PACE, S. Brand community of convenience products: new forms of customer empowerment-the case "My Nutella The Community". European Journal of Marketing, v. 40, n. 9/10, p. 1087-1105, 2006.

DIEM, A.; WOLTER, S. C. The use of bibliometrics to measure research performance in education sciences. Research in Higher Education, v. 54, n. 86 , p. 86-114, 2013.

FEYERABEND, P. Contra o método. Rio de Janeiro: Francisco Alves, 1977.

FOUCAULT, M. A ordem do discurso. São Paulo: Loyola, 2000.

FREITAS, G. K. A.; LEÃO, A. L. M. S. Concepção da netnografia da comunicação: uma abordagem aplicada à pesquisa em Administração. GESTÃO.Org - Revista Eletrônica de Gestão Organizacional, v. 10, n. 2, p. 211-228, 2012.

FÜLLER, J.; JAWECKI, G.; MÜHLBACHER, H. Innovation creation by online basketball communities. Journal of Business Research, v. 60, n. 1, p. 60$71,2007$.

GASKELL, G.; BAUER, M.W. Para uma prestação de contas públicas: além da amostra, da fidedignidade e da validade. In: BAUER, M. W.; GASKELL, 
G. Pesquisa qualitativa com texto, imagem e som: um manual prático. 5. ed. Petrópolis, Rj: Vozes, 2002. p. 470-490.

GEERTZ, C. Nova luz sobre a antropologia. Rio de Janeiro: Jorge Zahar, 2001.

GIESLER, M.; POHLMANN, M. The social form of Napster: cultivating the paradox of consumer emancipation. Advances in consumer research, v. 30, p. 94-100, 2003a.

GIESLER, M.; POHLMANN, M. The anthropology of file sharing: consuming Napster as a gift. Advances in consumer research, v. 30, p. 273-279, 2003b.

GOLDENBERG, M. A arte de pesquisar: como fazer pesquisa qualitativa em ciências sociais. 8.ed. Rio de Janeiro: Record, 2004.

HSING, C. W.; SOUZA, C. A. A metodologia de netnografia aplicada a sistemas de informação: investigação de comunidades virtuais de processos de negócios. In: SEMEAD- SEMINÁRIOS EM ADMINISTRAÇÃO, 16., 2013, São Paulo. Anais... São Paulo: FEA-USP, 2013. p. 1-15.

KOSKINEN, J. et al. How to use bibliometric methods in evaluation of scientific research? An example from Finnish schizophrenia research. Nordic Journal of Psychiatry, v. 62, n. 2, p. 136-143, 2008.

KOZINETS, R. V. "I want to believe": a netnography of the X-Philes' subculture of consumption. Advances In Consumer Research, v. 24, n. 1, p. 470-475, 1997.

KOZINETS, R. V. On netnography: initial reflections on consumer research investigations of cyberculture. Advances in consumer research, v. 25, n. 1, p. 366-371, 1998.

KOZINETS, R. V. The field behind the screen: using netnography for marketing research in online communities. Journal of marketing research, v. 39, n. 1, p. 61-72, 2002.

KOZINETS, R. V. Click to connect: netnography and tribal advertising. Journal of advertising research, v. 46, n. 3, p. 279-288, 2006.

KOZINETS, R. V. Netnografia: realizando pesquisa etnográfica online. Porto Alegre: Penso, 2014.

KOZINETS, R. V.; HANDELMAN, J. Ensouling consumption: a netnographic exploration of the meaning of boycotting behavior. Advances in consumer research, v. 25, n. 1, p. 475-480, 1998.

LAPERRIÈRE, A. Os critérios de cientificidade dos métodos qualitativos. In: POUPART, J. et al. A pesquisa qualitativa: enfoques epistemológicos e metodológicos. Petrópolis, RJ: Vozes, 2012. p. 410-436.

LEMOS, A.; VALENTIM, J. Cibercultura e infraestrutura de redes sem fio no Brasil. Comunicação \& Sociedade, v. 27, n. 45, p. 79-94, 2006. 
LÉVI-STRAUSS, C. Antropologia estrutural. Rio de Janeiro: Tempo Brasileiro, 1991.

LÉVY, P. Cibercultura. São Paulo: Editora 34, 2007.

MALINOWSKI, B. Argonautas do Pacífico Ocidental. São Paulo: Abril Cultural, 1978.

MATHWICK, C.; WIERTZ, C.; RUYTER, K. Social capital production in a virtual P3 community. Journal of Consumer Research, v. 34, n. 6, p. 832849, 2008.

MESQUITA, R. F.; MATOS, F. R. N. A abordagem qualitativa nas ciências administrativas: aspectos históricos, tipologias e perspectivas futuras. Revista Brasileira de Administração Científica, v. 5, n. 1, p. 7-22, 2014.

MIGUEL, S.; DIMITRI, P. La investigación en bibliometría en la Argentina: quiénes son y qué producen los autores argentinos que realizan estudios bibliométricos. Informacion, Cultura Y Sociedad, v. 29, p. 117-138, 2013.

MINAYO, M. C. S.; SANCHES, O. Quantitativo-qualitativo: oposição ou complementaridade. Caderno de Saúde Pública. Rio de Janeiro, v. 9, n. 3, p. 237-248, 1993.

MORIN, E. Ciência com consciência. Rio de Janeiro: Bertrand Brasil, 1996.

NELSON, M. R.; OTNES, C. C. Exploring cross-cultural ambivalence: a netnography of intercultural wedding message boards. Journal of Business Research, v. 58, n. 1, p. 89-95, 2005.

NOVELI, M. Do off-line para o online: a netnografia como um método de pesquisa ou o que pode acontecer quando tentamos levar a etnografia para a internet? Organizações em Contexto, v. 6, n. 12, p. 107-133, 2010.

POPPER, K. R. Conhecimento objetivo: uma abordagem evolucionária. Belo Horizonte: Itatiaia, 1999.

PRITCHARD, A. Statistical bibliography or bibliometrics? Journal of Documentation, 25, n. 4, p. 348-349, 1969.

RAISIG, L. M. Statistical bibliography in the health sciences. Bulletin of the Medical Library Association, v. 50, n. 3, p. 450-461, 1962.

ROCHA, P. J.; MONTARDO, S. P. Netnografia: incursões metodológicas na cibercultura. Revista Compós, v. 4, p. 1-22, 2005.

RUTTER, J.; SMITH, G. Ethnographic presence in a nebulous setting. In: HINE, C. (Ed.). Virtual methods: issues in social research on the Internet. New York: Berg Publishers, 2005. p. 81-95.

SANDLIN, J. A. Netnography as a consumer education research tool. International Journal of Consumer Studies, n. 31, p. 288-294, 2007. 
SANTOS, J. L. S.; KALSING, M.; HANSEN, P. B. Redes de cooperação interorganizacional: uma análise sistemática da produção científica na Web of Science de 1981-2013. In: SEMEAD - SEMINÁRIOS EM ADMINISTRAÇÃO, 17., 2014, São Paulo. Anais... São Paulo: FEA-USP, 2014. p. $1-15$.

SANTOS, J. L. S.; MALDONADO, M.; SANTOS, R. Mapeamento das publicações acadêmico-científicas sobre memória organizacional. In: ENCONTRO DA ANPAD (EnANPAD), 35., 2011, Rio de Janeiro. Anais... Rio de Janeiro: ANPAD, 2011. p. 1-15.

YIM, C. K.; TSE, D. K.; CHAN, K. W. Strengthening customer loyalty through intimacy and passion: Roles of customer-firm affection and customer-staff relationships in services. Journal of Marketing Research, v. 45, n. 6, p. $741-756,2008$. 